\title{
Challenges in natural language processing: the case of metaphor (commentary)
}

\author{
John A. Barnden
}

Received: 8 October 2009 / Accepted: 13 October 2009 / Published online: 19 November 2009

(C) Springer Science+Business Media, LLC 2009

\begin{abstract}
This article comments on some ways in which metaphor is relevant to practical language technology, for either text or speech. While the article mentions some deep problems, it nevertheless points out that certain issues are less troublesome than they might appear to be, and that metaphor in real discourse has some characteristics that could help, rather than hinder, practical discourseprocessing. The article also mentions the author's ongoing work on developing a new view of how metaphor and metonymy relate to each other. This view is based on a deconstruction into underlying dimensions.
\end{abstract}

Keywords Metaphor · Metonymy · Figurative language · Natural language understanding · Natural language technology $\cdot$ Natural language pragmatics · Discourse processing $\cdot$ Lexical resources $\cdot$ Language resources . Ontologies

Of the many challenges facing the practical application of natural language processing, there is one in particular that has seen especially little serious computational attention: namely the problem of metaphor. Although many researchers not in the metaphor area may be tempted to think of metaphor as a peripheral problem (perhaps mostly to do with poetry and other literary language) it is in fact a pervasive feature of mundane language (conversation, newspaper articles, popular science writing, etc.). See for instance many of the contributions to a recent metaphor handbook (Gibbs 2008).

J.A. Barnden $(\bowtie)$

School of Computer Science, University of Birmingham,

Birmingham, B15 2TT, UK

e-mail: J.A.Barnden@cs.bham.ac.uk
Equally, may researchers who might be prepared to acknowledge metaphor to be an important practical problem would nevertheless regard it as too difficult to tackle for the forseeable future. In fact, I believe this is also a misperception: certainly, the most difficult cases of metaphor are very difficult to deal with, requiring much pragmatic inferencing, but the same could be said of the most difficult cases of, say, anaphor processing. Much metaphorical language is either a matter of fairly fixed phraseology (though see below for a comment on this), or rests on familiar conceptual mappings in such a way that it is possible to see that manageable amounts of processing could be used to work out what information is being conveyed. In short, metaphor is both more important and easier than you think it is.

In my workshop presentation I explored some implications for ontologies, lexical resources, discourse handling and text mining of my work on ATT-Meta, a reasoning system designed to work out the significance of a broad class of metaphorical utterances (see for instance Barnden 2007, 2008). This class includes "map-transcending" utterances, resting on familiar, general metaphorical views (e.g., the view of IDEAS AS PHYSICAL OBJECTS) but going beyond them by including source subject-matter elements (elements concerning PHYSICAL OBJECTS in the case of that view) that are not handled by the source-target mappings established in those views. (The target subject-matter is the topic area that is actually being addressed by a metaphorical utterance.)

The ATT-Meta system relies heavily on doing reasoning within the terms of the source subject-matter rather than trying to construct new mapping relationships to handle the unmapped source elements. The reasoning tries to connect the unmapped elements to elements that are indeed mapped. The approach also advocates the use of only a small number of mappings per metaphorical view, compared to most other 
work involving similar constructs. We are able to economize on the view-specific mappings by relying also on a suite of "view-neutral mapping adjuncts" that perform, by default, many important types of mapping (e.g., of emotions, evaluations, qualitative time relationships, causation) irrespective of which particular views are in play. The approach therefore argues for including only relatively sparse sets of viewspecific metaphorical mappings in ontologies and lexical resources like WordNets, and for downplaying the need to facilitate the creation of new mappings.

A further observation arising from the research on ATTMeta concerns more-or-less conventionalized metaphorical phraseology, including metaphorical idiom. Although such phraseology is common in mundane discourse, and it is therefore probably beneficial to include some of it in lexicons and WordNet-like resources, the phraseology can be richly, systematically and open-endedly varied in ways that require ATT-Meta-style reasoning (Barnden 2007). (See also Langlotz 2006, and Moon 1998, on variation; and see the Langlotz article on the role of reasoning, cast there as metonymic acts within the source subject-matter.)

A more general insight, shared with a number of other researchers, is that while metaphor often does involve what we would normally view as qualitatively different domains (subdivisions of conceptual space, such as IDEAS on the one hand and PHYSICAL OBJECTS on the other), it often does not do so. So, while it may be useful to include explicit domain information within a lexical resource or an ontology, such information can at best be a heuristic guide in metaphor handling. A further general tenet in the ATT-Meta approach is the great language-user-relativity of metaphor: matters such as whether an utterance is metaphorical and, if so, what metaphorical views it rests on are not objective, and are instead determined by what lexical senses and metaphorical views the particular understander is familiar with. This has the practical benefit of releasing lexical resources and ontologies from having to respect supposedly objective decisions from other quarters about what is metaphorical and how. The user-relativity is also friendly to a view where the presence of a word-sense in a lexicon is a practical matter that has little to do with the theoretical issue of whether that sense is metaphorical or not.

Metaphor and metonymy, another practically important type of figurative language, are often (allegedly) distinguished by appealing to the claim that metaphor works between domains whereas metonymy works within a single domain. Given the above point about domains, and slipperiness in the very notion of a domain, there has been much debate about how better to distinguish metaphor and metonymy or whether they can be rigidly distinguished at all (Dirven and Pörings 2002). I have in ongoing work (Barnden in press) been seeking to view metaphor and metonymy in another way. I believe the difficulties can be resolved by recognizing them to be hazy, ill-defined concepts and accepting that what is important for technical research is certain underlying dimensions, concerned for instance with the extent to which various different sorts of mapping are involved. Particular sorts of metaphor and metonymy are just particular constellations of choices along those dimensions, and a rich space of compromises between metaphor and metonymy is open.

Metaphor is frequent in conversation, so that automated systems for handling dialogue in a natural and peoplefriendly way will eventually need to grapple with the phenomenon. However, the other side of the coin is that metaphor can be a useful guide to the structure of dialogue and to summarisation, because certain types of metaphor are often used by speakers to signal topic changes, to summarise a segment of dialogue that has just occurred or is about to occur, or to refer to the structure of the discourse itself (Cameron 2003; Drew and Holt 1998; Low et al. 2008).

Because of the fact that metaphor often does introduce source terminology that is qualitatively distant from the target subject-matter actually being talked about (consider, say, the common practice of talking about companies as eating each other) - although it does not always do this, as stressed above- it is a potential hazard in technology for information retrieval, information extraction, text mining, topic tracking, etc. For instance, a technique that looks for particular terms in texts could be deceived by metaphorical use of such terms. It would therefore be beneficial to be able to detect metaphorical segments even when the aim is not to understand them. The problem posed by metaphorical segments is especially acute when a metaphorical sentence or group of sentences is largely or wholly composed of source vocabulary, leaving the target situation implicit, so that immediate lexical context around a metaphorically used term gives little or no clue as to its metaphoricity.

Finally, one feature of metaphor that can help with the task of metaphor detection (especially of the less conventional varieties of metaphor) is that some occurrences of metaphor are signalled, in real discourse, by particular linguistic devices (Cameron and Deignan 2003; Goatly 1997). They range from morphological devices through lexical phrases to syntactic constructions. The devices do not necessarily signal metaphor when they occur, but do so usefully often. In my own work I have found the catalogue of signals in Goatly (1997) useful, though I have made considerable modifications (Barnden n.d.).

\section{References}

Barnden, J. A. (2007). Metaphor, semantic preferences and contextsensitivity. In K. Ahmad, C. Brewster, \& M. Stevenson (Eds.), Words and intelligence II: Essays in honor of Yorick Wilks (pp. 39-62). Berlin: Springer. 
Barnden, J. A. (2008). Metaphor and artificial intelligence: Why they matter to each other. In R. W. Gibbs Jr. (Ed.), The Cambridge handbook of metaphor and thought (pp. 311-338). Cambridge: Cambridge University Press.

Barnden, J. A. (in press). Metaphor and metonymy: Making their connections more slippery. Cognitive Linguistics.

Barnden, J. A. (n.d.). Possible signals of metaphoricity not linked to any particular conceptual metaphor. http://www.cs.bham.ac.uk/ $\sim$ jab/ATT-Meta/metaphoricity-signals.html.

Cameron, L. (2003). Metaphor in educational discourse. London: Continuum.

Cameron, L., \& Deignan, A. (2003). Combining large and small corpora to investigate tuning devices around metaphor in spoken discourse. Metaphor and Symbol, 18(3), 161-173.

Dirven, R., \& Pörings, R. (Eds.) (2002). Metaphor and metonymy in comparison and contrast. Berlin: Mouton de Gruyter.
Drew, P., \& Holt, E. (1998). Figures of speech: Figurative expressions and the management of topic transition in conversation. Language and Society, 27, 495-522.

Gibbs, R. W. Jr. (Ed.) (2008). The Cambridge handbook of metaphor and thought. Cambridge: Cambridge University Press.

Goatly, A. (1997). The language of metaphors. London: Routledge.

Langlotz, A. (2006). Idiom creativity: A cognitive-linguistic model of idiom-representation and idiom-variation in English. Amsterdam: Benjamins.

Low, G., Littlemore, J., \& Koester, A. (2008). The use of metaphor in three university academic lectures. Applied Linguistics, 29(3), 428-455.

Moon, R. (1998). Fixed idioms and expressions in English. Oxford: Clarendon Press. 